\title{
$=$
}

\section{La Circularidad de la Experiencia de Campo: poder y desigualdad en la producción del conocimiento}

\author{
Ana María Spadafora LA CRITICA ETNOGRÁFICA: LUGARES DE CAMPO Y TEMAS DE \\ FLACSO INVESTIGACION
}

En referencia a la razón espacial de la práctica etnográfica, Pablo Wright (1998) sugiere un análisis guiado por dos cuestiones claves. En primer lugar, la relación dialéctica que existe entre los lugares donde trabajamos y la clase de sujetos que dicha práctica produce y, en segundo lugar, la idea de que la economía política del conocimiento supone condicionamientos estructurales relacionados con la situación geopolítica de cada área en cuestión. Retomando parte de los estudios realizados en el marco de la llamada antropología crítica o reflexiva y de la antropología de la experiencia, surgidas en el seno de la academia norteamericana y europea, a partir de mi propia experiencia de campo analizo cómo la creación de lugares antropológicos constituye una práctica que se encuentra estrechamente vinculada tanto a la relación entre centro y periferia como a los procesos concretos de práctica disciplinar espacial y temáticamente localizados. Así, la consideración del campo en tanto lugares antropológicos que son reconocidos como tales en función de un proceso histórico y disciplinar de legitimación nos debería llevar a desnaturalizar las 'áreas de trabajo' y comprender su vinculación a una lógica de la práctica que desemboca en la acumulación de experiencias cristalizadas en estratos no siempre explícitos y del todo conformados a los que comúnmente nos referimos como "tradiciones" antropológicas (Wright 1998).

La aproximación crítica respecto a cómo interviene el background disciplinar en la etnografía se encuentra alineada a los análisis de J ohannes Fabian (1983) y Campos 4:135-154, 2003. Clifford Geertz (1983) que, con diferencias, abordan el carácter problemático de 
nociones como distancia, sitio y otredad en tanto éstas son ante todo categorías constitutivas de nuestra disciplina que actúan como fundamento y legitimación de la práctica etnográfica y sacralizan al etnógrafo como único traductor autorizado. J ohannes Fabian (1983), por ejemplo, plantea cómo la antropología en la construcción de su 'objeto de estudio' realiza un desplazamiento temporal. Para Fabian (1983) el proceso de alterización o construcción del Otro define a una práctica disciplinar cuyo punto de partida es el encuentro intercultural, lo que tiene profundas consecuencias epistemológicas. Los trabajos precursores de Clifford Geertz (1983) acerca del "punto de vista del nativo" y más tarde los desarrollos de sus principales discípulos, J ames Clifford y George Marcus (1986), apuntan básicamente a profundizar la crítica etnográfica entendiendo que el campo puede ser analizado como un texto y la antropología como un tipo de discurso literario destinado a consagrar la legitimidad del investigador por sobre la pluralidad de voces que de hecho conforman e intervienen en eso que la disciplina ha naturalizado como "trabajo etnográfico".

Al margen de las posibilidades efectivas de una antropología dialógica cuando de movimientos religiosos se trata, la crítica etnográfica se revela como un instrumento eficaz en la empresa de analizar criticamente el proceso de construcción del conocimiento "científico" que al involucrar a la literatura y las humanidades se transforma de hecho en una verdadera opción política (Garma Navarro 1991). Estas perspectivas enfatizan las condiciones de surgimiento de la antropología, su vinculo con las prácticas coloniales y todo lo que ello acarrea desde el punto de vista de la relación entre Occidente y la otredad. Así, por ejemplo, buscan desenmascarar todo lo que categorías como "indio" o "paganismo" tienen de constructo histórico, esto es, como fruto de un contexto de relaciones asimétricas entre 'nosotros' y la 'alteridad', relaciones que en la practica etnográfica apuntaron a legitimar un genero discursivo (el del etnógrafo) por sobre los demás (de los nativos). Siguiendo estos lineamientos, tanto la 'elección' del espacio de campo así como del 'tema' constituyen desde el inicio elementos sumamente críticos en todo proceso de investigación y en el tipo de conocimiento que a la zaga producimos, elementos que, sin embargo, deliberadamente o no excluimos sistemáticamente de nuestros resultados.

Como parte del intento de "des-exorcizar" algunos episodios de mi propia experiencia de trabajo con grupos pentecostales "urbanos" en la década de los 90, este trabajo propone un ensayo exploratorio de la situación de campo desde un abordaje abierto a la "explicación nativa" en su manera de dar sentido a la propia existencia. De esta manera analizo la experiencia de campo involucrando algunas creencias y sueños que se nos presentaron en etapas previas y durante el trabajo de campo. Considero que, en cierta medida, la incorporación de estas otras instancias, comúnmente invisibilizadas por la lógica racionalista que guía el trabajo de campo, constituye un ejercicio interesante para el análisis crítico de la producción etnográfica, muy especialmente de la manera en que 
los prejuicios antropológicos - centrados en la revalorización de lo prístino, lo auténtico y lo nativo - y las propias creencias - que tienen como referente ya explícito, ya implícito al modelo de religiosidad católica - intervienen en nuestra labor.

Reproduciendo el carácter paradigmático de las historias de vida de los creyentes pentecostales, la autobiografía del pastor despliega su trayectoria desde un pasado descreído y gobernado por las fuerzas del Mal - tematizado como alcoholismo, drogas y el delito - hacia un presente iluminado por la Palabra de Dios. Este itinerario nos aporta ciertamente una enseñanza pedagógica en la medida que permite explicitar nuestro 'transitar por el campo' en un recorrido de doble mano: desde la razón del pensamiento científico hacia la creencia que solapadamente filtra nuestro propio trabajo y, finalmente, desde la creencia hacia la razón buscando comprometer aspectos vinculados a sentimientos no contemplados pero que sin embargo impregnan la lógica de nuestro trabajo. Tenemos la convicción que invertir la lógica explicativa de la experiencia subjetiva y de alguna manera recuperar parte de la "teoría pentecostal de los sujetos" es un saludable ejercicio para repensar desde una perspectiva crítica la empresa etnográfica y, en particular, recapitular nuestra propia relación con el campo.

\section{PRIMERA CONFESIÓN: ESPACIOS Y TEMAS}

Es difícil explicar cuando realmente comencé mi trabajo como antropóloga. Mi madre, Susana Santini, también antropóloga, se ocupó desde mi más tierna infancia de inculcarme la vocación con una devoción inusitada. Eran los años 70 cuando recorría las villas de San Francisco Solano acompañándola en sus entrevistas de campo. Tenía 8 años de edad y me había tomado en serio la "observación participante" frente a un mundo marginal que me resultaba más repulsivo que exótico, aún cuando esa pobreza, comparada con la Argentina actual, tenía mucho de dignidad. Esa experiencia angustiante contrastaba con los objetos y fotos de "tribus primitivas" que lucían en las "vidrieras" de los museos antropológicos y la literatura infantil a la que estaba acostumbrada, caminos siempre abiertos a la imaginación. Prolijamente frecuenté clases magistrales en el Museo Etnográfico registrando el "folklore" y las tradiciones de pueblos siempre distantes, ajenos y detenidos en el tiempo. Recuerdo el respeto que me provocaban las salas del Museo de La Plata o los olores rancios del Museo Etnográfico donde apenas unos pocos estudiantes seguían los pasos de nuestros padres míticos. En mi, todo era devoción. Resonaban en mi oído nombres en guaraní y largas horas me dedicaba a acariciar las preciadas piezas que allí se exhibían con la constante esperanza de un buen día finalmente escapar hacia esos otros lugares. 
En 1983 en un clima de efervescencia y algarabía social me inicie en la vida democrática y de estudiante en una universidad saludablemente dispuesta a transformarse y transformar la sociedad. Mitos y ritos de sociedades primitivas cedían lugar a los 'nuevos problemas de la antropología': "la pobreza" y "el campesinado" remplazaban rápidamente a los "indios". El sueño de infancia del incansable viajero se desvanecía sobre una realidad menos simpática y más atenta a otro tipo de problemáticas que poco a poco se fueron recortando como 'antropología social' en un intento por diferenciarse de la 'etnografía y etnología'. Me recibía defraudada, leyendo EI XVIII Brumario de Luis Bonaparte de Karl Marx y convencida de que sobre la faz de la tierra arrasada por el capitalismo ya no había un solo 'indio' ni lugar donde escapar y que, por lo tanto, la labor del etnógrafo no estaba allá sino acá.

No casualmente estos cambios que se me planteaban y que yo no llegaba a percibir claramente fluctuaban entre el allá y el acá. La redefinición del lugar y del tiempo en el campo así como del etnógrafo en tanto observador privilegiado ciertamente hundían sus raíces en lo que no era mas que el sentido que definía nuestra práctica disciplinar. La identidad disciplinar espacialmente anclada en el allá que tanto había nutrido mi infancia no se condecía entonces con el acá que promovían las nuevas preocupaciones académicas desde el inicio de la democracia. Paradójicamente el destino me llevó a realizar mi primer trabajo de campo en lugares que parecían estar mas cerca del exotismo que de las formulaciones apocalípticas que se planteaban en la universidad acerca de la desaparición de las sociedades indígenas. Mi primer trabajo de campo entre los nivaclé del Chaco Boreal Paraguayo fue ciertamente una experiencia iniciática y existencial que modificó para siempre la vulgar idea de la inexistencia de indígenas y, sobre todo, equilibró mi sentido un tanto alterado de la diferencia, la mismidad y la otredad permitiéndome situar de manera realista en lo que parecía mas formar parte de una florida literatura que de la situación real en la que se encontraba una parte de la humanidad.

Los 90 me plantearon finalmente la encrucijada de decidir si mi investigación iba a centrarse en el aquí o en el allá. Una inesperada noche en pleno potlach navideño caminando por la Avenida Rivadavia vi por primera vez al pastor Giménez, un conocido pastor evangélico, pilar - junto a su esposa Irma - del Ministerio "Ondas de Amor y Paz". Vestido de negro y con corbata blanca parecía un mafioso salido de cualquier película norteamericana que, cortando la calle adornada con bombitas de colores, pronunciaba una arenga enérgica y festiva ante los fieles que se agolpaban a su alrededor: "Hermanos en esta noche de gloria ya no hay tiempo, J esucristo vendrá a Salvar la Iglesia", mientras fieles y transeúntes se entregaban a una música resonante y desafinada que brotaba ensordecedora desde los parlantes. A mis ojos, la escena resultaba tanto o más exótica que cualquier práctica de chamanismo africano, por lo que por vez primera logré sentir que el allá y el acá se reconciliaban para dar finalmente tranquilidad a mi alma y tuve, casi como una premonición, la certeza de que allí estaba mi verdadera "vocación". 
La situación en la academia antropológica local con respecto al 'tema' de mi elección no colaboró a contener mi indecisión. La ausencia de investigaciones sobre este tipo de iglesias devenía al menos en parte de un cierto recelo, no hacia los evangélicos, aunque sí hacia personajes como Giménez, recelo constatable en la sospecha acerca de su legitimidad como líder religioso. No en pocas ocasiones, aunque de manera siempre informal, me encontré en el apuro de aclarar por qué Giménez y su iglesia podían constituir un tema legítimo de investigación y no meramente un caso policial o en el mejor de los casos una nueva constatación de cómo la religión constituía todavía hoy el "opio de los pueblos". En estos aspectos, las sospechas de la legitimidad religiosa del pastor por parte de la academia antropológica no parecían diferenciarse en demasía de los estigmas que el periodismo local - reconocido como único legítimo analista del 'fenómeno sectas' - depositaba sobre su iglesia. Y es que en los 90 la legitimidad religiosa de iglesias como las del Pastor Giménez estaba en serias dudas. El "fenómeno Giménez" y su desenfadada esposa Irma acaparaban los titulares más escandalosos de la prensa amarilla empecinada en perpetuar estereotipos bajo la acusación de "sectas", "iglesia electrónica”, "negocio de unos pocos" o "lavado de cerebro", contribuyendo a potenciar el carisma "natural" del pastor y sus ideas acerca de "la necesidad de arrebatar las telecomunicaciones en manos de Satán para devolverlas a los legítimos herederos del Señor" (Giménez 1993).

Su popularidad, sin embargo, era inversamente proporcional al desconocimiento que los medios de comunicación y la academia tenían de su iglesia, de sus creencias y muy especialmente de quienes se acercaban a ella, popularidad que devenía tanto de sus fieles como de la pronunciada actuación de Giménez en los medios de comunicación. Esta situación me forzó a una investigación que nunca podía librarse del todo de una continua deconstrucción de términos, significados y estereotipos promovidos desde los medios de comunicación y que en esos tiempos rondaban enérgicamente a los mas conocidos creyentes y pastores del "mundo evangélico" como así también a los practicantes de las religiones afro brasileñas como la umbanda, acusados sistemáticamente de sacrificios de animales y otras 'prácticas deshonestas'.

Es por eso que en este escenario de inicios de los 90 el impacto social del pentecostalismo (y muy especialmente el protagonismo mediático de la iglesia del pastor) era inverso también a la existencia de análisis antropológicos, tarea que recaía en buena medida en la "Sociología de la Religión" que comenzaba a mostrar su preocupación por las 'nuevas alternativas religiosas' y que se mostraba más permeable a la convivencia con "sospechosos híbridos" con los que la antropología (local y no tanto) no tenía armas teórico-metodológicas adecuadas para lidiar. Así, los antecedentes de investigación sobre pentecostalismo en la antropología local se limitaban a análisis de iglesias pentecostales en sociedades indígenas enfatizando cómo estas iglesias, especialmente la Iglesia Evangélica Unida, habían podido introducir su mensaje a partir de una serie de similitudes que presentaban 
con las concepciones religiosas de las sociedades etnográficas, operando un proceso de resignificación (Cordeu y Siffredi 1971 y 1973; Siffredi 1975/76; Miller 1979; Cordeu y De los Ríos 1982; Wright 1988, 1990, 1994a y 1994b).

Aún cuando básicamente las iglesias pentecostales tenían el mismo horizonte de creencias, se diferenciaban de iglesias como las de Giménez que acentuaban determinados aspectos - como por ejemplo la idea de que J esucristo "prospera" a quien se acerca a su iglesia y el uso intensivo de los medios de comunicación - que las hacían algo distintas, diferencia que les valió el nombre de "neopentecostalismo" (Oro 1992). De hecho, el término neopentecostalismo buscaba caracterizar a las iglesias protestantes pentecostales surgidas con posterioridad a la década de los 50 a fin de distinguirlas de las establecidas en el país a partir de misiones extranjeras en el inicio del siglo XX (Wynarczyk y Semán 1994). Es por eso que aún cuando en el momento en que inicié mi investigación "la academia antropológica local" mostrara una apertura hacia otro tipo de temáticas que habían dado en llamarse 'antropología social', los referentes teóricos - explícitos o no - seguían teniendo como modelo a las "sociedades etnográficas", una antropología que en los hechos se asentaba en cánones disciplinares, presupuestos, categorías y herramientas metodológicas que, explícita o implícitamente, continuaban abrevando en las riberas de lo exótico, lo tradicional y lo ajeno, aún cuando pretendiera renegar de ello.

Esta situación (sin que lo supiera claramente en ese momento) marcaría a fuego el tipo de relación que establecí con los "informantes" y por lo tanto el devenir de mi investigación provocándome una reiterada aflicción por lo que entendía como una mala elección personal del "objeto de estudio" y no como el resultado lógico de una tradición disciplinar anclada en referentes que, aún cuando parecían diferenciarse radicalmente de la práctica antropológica tradicional guardaban con ella profundas relaciones que solo con el tiempo pude descifrar.

\section{SEGUNDA CONFESIÓN: SUJ ETOS Y CUERPOS}

En 1991 gracias a una beca otorgada por el CONICET inicié finalmente mi investigación en el templo central de la Iglesia "Ondas de Amor y Paz" de Giménez y su esposa Irma, situada justamente donde por vez primera había visto al pastor. Sin embargo, la situación real no se condecía con la "tranquilidad" aparente que había ganado en mi interior con la elección del "lugar" y el "tema". De hecho, la peor de las batallas aún estaba por librarse y con la ignorancia de una neófita - me acerqué a un "campo" que en ese momento se me hacía menos al mundo exótico y amable de los manuales bíblicos de la antropología y más a un verdadero campo de batalla de 
significados. Mi primer registro en mayo del 91, rezaba:

"Hay algo que no cierra. El predio de la "iglesia" de Giménez corresponde al del ex cine Roca sobre la Avenida Rivadavia. Hombres y mujeres se pasean de un lado al otro entre el templo y lugares aledaños que corresponden a las nuevas adquisiciones de Giménez para hacer su centro de estudios bíblicos, su mutual, su espacio para los jóvenes. Molestan estos señores y señoras que a pesar de su aspecto mas que mundano, Biblia en mano, aseguran que el 'fin de los tiempos' ya está cerca. Alteran definitivamente la geografía del barrio con una estética no del todo respetuosa de los viejos escenarios de Almagro".

Ciertamente, mi anterior experiencia de campo - realizada junto a Alejandra Siffredi - la hacía honor a la tradición de áreas geográficas espacialmente delimitadas, lejanas y eternamente ancladas en el tiempo. De hecho, en el Paraguay había una familiaridad ostensible con el etnógrafo, tanto de parte de los indios como por parte de la sociedad y muchos de los grupos indígenas del interior del Chaco seguían "conservando sus tradiciones", aun cuando ello era el resultado de un aislamiento obligado o, en otros casos, de la falta de apetencia por parte de los blancos de las pobres tierras que, merced al confinamiento, ocupaban los indígenas. La familiaridad con el etnógrafo era tal que uno de nuestros interlocutores - a la sazón un importante dirigente indígena - quedo francamente sorprendido cuando en la primera entrevista comparo nuestro humilde grabador con el moderno equipo que según él, utilizaba el famoso antropólogo Pierre Clastres con quien había trabajado.

Aquí en Buenos Aires no solo no había "aldea" sobre la cual reparar, tampoco había la menor intención de recoger a una inocente principiante que, grabador y cuaderno en mano, se disponía a "registrar" todo lo que pasaba frente a sus ojos. Mi primera entrevista fue una lucha por explicar ni más ni menos que al tesorero y secretario general de la iglesia que no era una enviada de Satán y que mi intención no era el espionaje periodístico y mucho menos la persecución ideológica. Las valoraciones negativas atribuidas a los evangélicos y especialmente a Giménez y su iglesia a las que nos referimos, tanto por el uso sistemático e intensivo de los medios de comunicación como por el tipo de creencias y prácticas religiosas que sostenían, conspiraban en la consideración del evangelismo en términos positivos. La imagen negativa externamente propulsada tenía en la construcción del "fenómeno sectas" un elemento explicativo mas que crucial.

Sin embargo, había razones menos obvias y más profundas. Concretamente, las prácticas religiosas de los evangélicos - centradas en el éxtasis como forma de experienciar la fe religiosa - resultaban extrañas a un modelo sociorreligioso que - mas allá de la adhesión deliberada o no - se estructuraba históricamente en la hegemonía cultural del catolicismo. Así, las diferencias entre los cultos extáticos de los evangélicos y la liturgia cristiana ortodoxa - tanto católico como protestante - colaboró en la consolidación de la imagen una y otra vez reiterada por los medios de comunicación y la sociedad de que los fieles de Giménez eran víctimas del pastor y que eran 
engañados y atrapados en una especie de histeria colectiva que los sumía en las más irracional de las efervescencias. En los inicios de mi investigación esta imagen conspiró contra una comprensión genuina de los cultos como verdaderas expresiones religiosas que ponían en acto una profunda fe vivida por parte de quienes se integraban a ellos. En contrapartida, los creyentes de Giménez, lejos de restringirse a recibir pasivamente el mensaje (como sí parece ocurrir en algunas iglesias norteamericanas) se integraban a la iglesia a partir de lazos de parentesco reales o rituales que, como se ha constatado en otros casos, permitían formar una red social extensiva (Galliano 1994; Spadafora 1996). Es por eso que el seguimiento de programas radiales y televisivos "evangélicos" y la participación en campañas de gran escenificación actuaban mas como una confirmación de lazos preexistentes que como medios efectivos de reclutamiento de adeptos, tal como señalaban los medios de comunicación y como se creía desde el imaginario de los informantes y pastores que promovían la necesidad de realizar estos eventos a los fines de reclutar adeptos. Paralelamente, el carácter fuertemente carismático de la religiosidad neopentecostal otorgaba a los cultos una singularidad propia, recortada sobre la base de prácticas y percepciones que apuntaban a reafirmar la fe no solo como creencia sino, fundamentalmente, como experiencia.

A pesar de mi familiaridad con el perfil carismático de los pastores evangélicos y con el significado que el éxtasis tenía para los sujetos en el horizonte de creencias pentecostales, en los inicios de mi investigación tuve serias dificultades para aplicar en los hechos lo que sabia por la razón. Ello podía constatarse en la fluctuación de mis escritos de campo donde reiteradamente me debatía en el estatus que finalmente debía asignarles: "culto bailanta"; "altar - escenario"; "fieles - seguidores", términos reiterados e intercambiables que soslayaban mi profunda resistencia hacia la experiencia religiosa de los creyentes y su autenticidad desde un punto de vista genuinamente espiritual. Así, mi primera descripción de un culto aunque reflejaba casi como una fotografía lo que de hecho ocurría, mostraba una severa "confusión" donde el uso entreverado de los términos mostraba claramente las dudas acerca del carácter "verdaderamente" religioso de sus prácticas. Por ejemplo:

“Dentro del templo, sube la temperatura. Nada de "templo" o “iglesia” o... ¿ cómo llamarle? Tal vez bailanta sería mas apropiado para describir un escenario que nada tiene de altar y un culto que nada tiene de misa".

O bien:

“Para cualquier neófito acercarse a un templo pentecostal recuerda mas a los salones de bailanta que al formalismo de las iglesias cristianas tradicionales. Montadas en plazas, carpas o antiguos cines y teatros suelen disponer de grandes equipos musicales y luces que contrastan francamente con la ceremoniosidad de los altares. El telón de 
fondo del escenario del viejo cine Roca sobre el que se montaba el templo central, cambiaba semana a semana gracias a la artesanal confección de los creyentes".

Así, los "equívocos" terminológicos ponían en acto mi incapacidad de ver los cultos como totalidades que - por medio del éxtasis - comprometían el cuerpo para "alabar al Señor", de manera tal que toda manifestación de Dios no era otra cosa que una expresión de fiesta y algarabía. Concretamente, el valor de la experiencia de fe entendida como descenso del Espíritu Santo sobre el creyente y que se expresa en temblores, desmayos y glosolalia otorgaba el carisma tan preciado por los seguidores de pastores que como Giménez comprometían en cuerpo y alma la participación de las personas. Esta especificidad es la misma que daba un carácter performativo a los cultos y las prédicas evangélicas, mostrando la importancia de la religiosidad no solo en términos doctrinales sino estéticos. Como señala Frigerio (1994), pastores exitosos como Giménez son también oradores carismáticos que brindan una dimensión estética muy apreciada por sus seguidores. Esta dimensión, crucial como referente religioso, puede constatarse en la importancia que tiene para los creyentes el uso de determinado tipo de vestimenta, la importancia que estos asignan a unas formas de expresarse, caminar y conversar; utilizan un diálogo estereotipado tendiente a reafirmar "la presencia de J esucristo en la conversación y que nos permite distinguir a cristianos de quienes no lo son" (Rosa, entrevista de campo, 1993).

Desde una perspectiva teórica, William O. Beeman (1993) sistematizó los aportes de la antropología de la performance para referirse a dimensiones de la vida humana como la religión, la política, las relaciones de género y la identidad étnica. La noción de performance, surgida de las artes del espectáculo, fundamentalmente del teatro, sirvió así como modelo e inspiración a muchos antropólogos interesados en abordar las prácticas sociales desde un encuadre que contemple la experiencia y sus dimensiones estéticas. Nos referimos a aspectos como la actuación y presentación de la persona indagadas por Erving Goffman (1981), la representación y la conducta personal analizadas por Clifford Geertz y, fundamentalmente, a las exploraciones de Victor Turner (1982, 1988, 1992) que focalizan el comportamiento corporal y la representación del cuerpo. Retomando la perspectiva del teatro en el análisis del ritual conceptualizado en términos de "drama social" (Turner 1982) y posteriores aportes realizados en sintonía con Schechner (1988) a los "performance studies" y la "antropología de la experiencia", las exploraciones de Turner permiten devolver la integridad y la vitalidad a experiencias que, como los cultos evangélicos, no podrían capturarse desde un análisis meramente racional, a menos de traicionar su espíritu.

Desde la perspectiva de la experiencia artísticaJ ulia Elena Sagaseta (1991), por ejemplo, señala la performance como cruce de múltiples expresiones como la danza, la plástica, la música, el teatro y los medios audiovisuales que hacen de la dimensión estética una dimensión crítica de determinadas prácticas sociales. Así el culto pentecostal en su integración de la fiesta se encuentra emparentado con ciertas prácticas religiosas presentes en la religiosidad 
popular donde oratoria, canto, baile y dramatización otorgan una especificidad a los cultos que los vuelve difícilmente comparables a la formalidad de las ceremonias religiosas de las iglesias cristianas tradicionales.

Pero el carácter performartivo de los cultos se ensombrecía a la luz de los prejuicios antes mencionados y de la incapacidad de explicar prácticas que comprometían al creyente en cuerpo y alma, compromiso que no encontraba espacio en el discurso racional que gobierna la antropología de la religión. En referencia a ello, Rita Segato (1988) sostiene que esta clase de discurso tiende a soslayar otras dimensiones que resultan más fértiles en tanto fieles a la naturaleza de lo sagrado, mostrando la inconmensurabilidad entre la lógica de la creencia y una lógica de la ciencia que actúa en pos del principio de inteligibilidad. En un replanteo de su investigación sobre los cultos xangó de Recife señala que la omisión de la asignación de 'coincidencia' entre determinado orixá y su propia personalidad - reiteradamente producida en el juego adivinatorio de caracoles - muestra que en el proceso de producción de conocimiento la antropología puede no solo negar sino incluso prescindir de las explicaciones nativas, aún cuando estas sean centrales e ineludibles para los otros (Segato 1993:34).

En realidad, no se trata tanto de reparar en la supuesta "inconmesurabilidad" de ambas lógicas dado que, a diferencia de Segato (1993), considero que no hay razón para pensar que una lógica debiera reducirse a otra. En todo caso, se trata de llamarnos la atención acerca de los conflictos surgidos en todo proceso de traducción y particularmente en aquellos que involucran creencias y experiencias religiosas, problema que ha sido oportunamente analizado por Victor Turner (1992), quien en su análisis de los aspectos performativos de ciertas instituciones sociales como la religión buscaba justamente considerar otros aspectos no contemplados por la práctica etnográfica y sin embargo significativos desde el ángulo de las instituciones sociales, sus sujetos y sus prácticas.

Volviendo al caso que me ocupa, pese a mi familiaridad como antropóloga con la repulsión que ciertas prácticas culturales podían generar en la labor de campo - tal como podía constatarse en los distintos géneros discursivos que dieron vida e imaginación a la etnografía - el éxtasis de los creyentes me provocaba un gran rechazo, aunque nunca me hubiera sincerado a mí misma. Los desmayos y temblores casi siempre me hacían transpirar y no pocas veces mareada debí salir del recinto a tomar "oxígeno". En esas situaciones no encontraba manera de relajarme. Algunas veces permanecía silenciosa de la mano de los creyentes esperando pacientemente que finalizara. Otras, huía desesperada sin poder soportar el zumbido que la efervescencia de los presentes provocaba en el interior del templo. Ese rechazo, como dije, nunca fue del todo confesado en mis escritos ni en mi persona, resignándome - en parte como una especie de expiación de viejas culpas cristianas, en parte como parte del oficio - a perseverar en el sacrificio de "aguantar" el miedo que esas situaciones me provocaban. 
Había también otras motivaciones. En el inicio de mi investigación quedé embarazada y a pesar de mis renovados esfuerzos por situarme como "antropóloga" no lograba desentenderme de las recurrentes asociaciones que llevaban a mis interlocutores a asociarme con el "periodismo", cosa que debido a la persecución sostenida por parte de los medios no gozaba de buena prensa entre la gente. En compensación, el embarazo me permitió gozar de cierta protección y reconocimiento y mis interlocutores acariciaron repetidamente mi panza, reiterándome que si yo estaba allí era en definitiva por "el plan que el Señor tenia para mí y para mi hijo". Inconscientemente desestimé la importancia que esas referencias podían provocar en mí y el miedo que, de hecho, me provocaban los comentarios acerca del nacimiento y la salud de mi hijo. Pero si estos y otros sentimientos no se plasmaban en los cuadernos de campo, sí lo hacían en los anárquicos dibujos que bordeaban mis escritos - poblados de demonios y ángeles imaginarios que se debatían en una incansable lucha entre el Bien y el Mal - y en mis reiterados esfuerzos por no olvidar pertenencias personales en casa de interlocutores y en el templo por temor a que finalmente pudiesen utilizarse con 'fines poco claros'.

Nuevamente fue el tiempo y, fundamentalmente, un profundo cambio de óptica el que me permitió desterrar los absurdos fantasmas con los que conviví a lo largo del campo. Pero esos cambios - que a la zaga me permitieron "ver" los cultos pentecostales como expresiones de una profunda fe religiosa - no provinieron de mi adiestramiento en la lectura teórica, donde no encontraba referentes ajustados a lo que se me presentaba, sino de un cambio de óptica que renegando justamente de las prácticas disciplinares tradicionales, me permitió ampliar mi horizonte analítico y, muy especialmente, mi entendimiento de la iglesia y sus pastores. Paralelamente, mi socialización en un horizonte católico de rígida observancia que buscaba la fe en el recogimiento personal mas que en la expresión colectiva, en el silencio mas que en el bullicio y en la solemnidad y el respeto a las reglas mas que en la expresividad del cuerpo y la palabra, conspiraron contra mi percepción de los cultos como verdaderas fiestas religiosas en las que se despliegan sentimientos colectivos de una impresionante perseverancia de fe.

\section{TERCERA CONFESIÓN: EL SUEÑO, INTERPRETACIÓN Y TRAICION}

En el invierno de 2000 ya estaba dispuesta para lanzarme a la escritura de mi tesis de doctorado. Antes de ello, y casi a manera de despedida había pensado en realizar un último trabajo de campo en el predio que recientemente había adquirido el pastor y su iglesia y a quien hace tiempo había dejado de frecuentar. Un poco motivada, otro poco apresurada a dar un cierre a mi trabajo y redactar la tesis, tomé coraje y me lancé al nuevo local que en el 
Barrio de Flores había adquirido un no ya tan exitoso y algo mas deteriorado pastor. El nuevo predio era de poca monta y hasta hace poco había funcionado como discoteca. La decoración era sobrecargada. Como un caleidoscopio, las paredes del amplio local estaban cubiertas de espejos que reflejaban los espacios simétricamente acompañados por luces de colores. Una luz negra impregnaba todo el lugar y apuntaba especialmente sobre la leyenda inscripta en el frente del escenario: "El Pastor Giménez presenta a J esucristo", sobre la que se recortaba la figura de un Giménez ya maduro que con énfasis replicaba:

“En estos duros tiempos, el Espíritu de Sacrificio - como bien nos enseñaron J osé y Moisés - es fe, es corazón y es razón, lo que gobierna la inteligencia. El sacrificio, hermana y hermano, es importante porque no se llega a lo que uno quiere si no es con Espíritu de Sacrificio. Pero no te engañes hermano. El sacrificio es corazón pero también es inteligencia para discernir cuando hay que actuar, que debemos hacer. Los cobardes no escriben la Historia, no es el Cielo para ellos y la violencia espiritual es consecuencia del Espíritu de Sacrificio".

La arenga me resultaba conocida. Desde siempre el discurso emblemático del pastor no era muy distinto al del resto de los pastores del mundo evangélico y podría sintetizarse en la frase ‘’ esucristo sana, libera, prospera y vuelve como Rey" y que resume el ideario pentecostal enfatizando uno u otro aspecto según la denominación (Wynarczyk y Seman 1994; Spadafora 1994, 1996). La salud, la pobreza, las drogas, son problemas recurrentes de los fieles que se suman día a día a las filas del pentecostalismo pero a lo largo de los últimos diez años, la rutinización de su carisma ha ido de la mano de una especie de radicalización de su mensaje que, tangencialmente, hace comentarios críticos acerca del poder, el dinero y la violencia institucional y que, de alguna manera, dan una impronta particular al mensaje evangélico. Ya en el año 1996, la formación de la Unión Europea fue interpretada por el pastor como señal del poder de Satanás sobre la Tierra a partir de la profecía de Daniel (7: 2-8) que decía “cuatro Bestias se alzarán del mar. La cuarta bestia espantosa y terrible en gran manera tenía dientes de hierro y diez cuernos" a los que se interpretaba como símbolos de 10 de las 12 naciones que, integrando la UE, demostraban el poder de Satanás como primer paso hacia el Apocalipsis final, hecho que lo llevo en una de sus tantas giras para "dar paz a las almas de la Alemania unificada" y a desviarse a Bruselas, una de las cabezas de la UE, para rezar contra Satán. A la imagen profética de la consolidación de la UE como una prueba del poder de Satán sobre la tierra, que promovía en los 90, sucederán incisivas arengas en las que sistemáticamente se cuestiona "el orden del mundo", "el sufrimiento del pueblo de Dios" y "la necesidad de que se haga justicia aquí y ahora". Pero la "sed de justicia" solo se calmara cuando el "espíritu de sacrificio" lejos de agachar la cabeza y poner la otra mejilla permita al creyente tomar fuerzas y adoptar la valentía necesaria como para "desenfundar el arma” y finalmente atreverse a escribir la Historia de quienes la tienen negada. 
Quien era si no Giménez, de voz ronca y pocos amigos... "Violencia espiritual". Esa frase quedo grabada en mi mente y en ese momento recordé cómo Giménez relataba su propia historia como una historia de perseverancia en la que Dios había llegado en el momento preciso para arrancarlo finalmente del oscuro mundo de las almas marginadas. Un ejemplo mas que claro de que la religión finalmente no era el "opio de los pueblos" y que en los "nuevos tiempos" de Giménez la Biblia bien podía adquirir las connotaciones de una poderosa arma. De hecho, Giménez era tanto el pastor carismático mas mediático del evangelismo como un personaje mas dentro de esa otra Argentina no tan exótica ni tan lejana. Hijo de una numerosa familia que en la década de los sesenta tuvo que abandonar su humilde casa para mudarse al conurbano, una historia de agravios, problemas económicos y enfermedades familiares lo llevara a enrolarse en el delito y sumarse al "oscuro infierno de las drogas y el alcohol". En 1972, a los quince años de edad - "totalmente entregado a la suerte de mi propio destino" - ingresó por primera vez a un reformatorio, hecho que se repetiría, entre persecuciones policiales y juzgados de menores, a lo largo de los dos siguientes años. Entre los abusos repetidos por parte de las instituciones policiales que - a pesar de tratarse de un menor y contrariar la orden del juzgado de menores de devolverlo a sus padres - insistían en mantenerlo en el reformatorio, volvió una y otra vez al delito hasta que, herido de bala luego de un robo, decidió iniciar una nueva vida: "En ese momento sentí que una nube me envolvió, y salí caminando del policlínico".

Los tiempos han cambiado. Si bien no se han cumplido las viejas profecías bíblicas (Spadafora 1994) que auguraban el final de los Tiempos como había profetizado Daniel, las nuevas alianzas políticas - globalización mediante - han confeccionado un panorama local e internacional en el que una nueva y velada forma de violencia se apodera de una sociedad cada vez mas fragmentada que ve perder lentamente sus sueños y aumenta sus privaciones. En ese contexto, "violencia espiritual" parecía ser entonces la respuesta de quien finalmente parece haber entendido que cuando el mundo no cambia es uno quien debe tomar la decisión de tomar "la Biblia como quien empuña un arma". Con las luces y música a toda marcha, "Pocho la Pantera" - el conocido cantante bailantero - se asomaba al "escenario" y animaba a la gente a bailar al compás del popular tema de la cubana Celia Cruz: “... Ay, no hay que llorar, que la vida es su carnaval..."

Regresé a mi casa. Por la noche tuve un sueño. Un Giménez joven con un impecable traje blanco y camisa negra, el mismo de mi primer encuentro esa noche de Navidad por la Avenida Rivadavia adornada con bombitas de colores, me invitaba a sumarme a la fiesta. Tímidamente yo me acercaba despacito y él, insistente, me extendía su mano. A su lado podía ver la gente que lo ovacionaba. Acercando su boca a mi oído me decía en voz baja: "nunca te gustamos porque siempre fuimos para vos negros, cabecitas negras del interior". Desperté sobresaltada y casi como en una película se sucedieron con la rapidez de un rayo imágenes que texturaban episodios de la vida de Giménez en los internados, sentí el olor penetrante de su perfume dulzón cuando acercándose en el sueño me 
murmuro: "todos negros... todos negros". En ese momento vino a mi mente el recientemente muerto cantante de cuarteto, Rodrigo, y su canción mas popular cuyo titulo no casualmente reza "INRI, la mano de Dios" y que evocando la historia de Diego Maradona recrea el camino paradigmático de quienes como el jugador un buen día finalmente lograron brotar de ese oscuro mundo de tinieblas del que solo la buenaventura podía finalmente dar vuelta. Oscuro mundo donde pobreza y marginación se aunaban para dibujar un destino casi impreso a fuego. El potrero o la villa, después de todo no eran muy distintos. En uno de sus escribillos en los que rememora la adicción a la droga del jugador dice así: “Cargo una cruz en los hombros por ser el mejor, por no venderse jamás al poder enfrento. Curiosa debilidad, si J esús tropezó, porque el no habría de hacerlo". Ahora, pobreza y drogas venían a solventar la fama de quienes como J esucristo no eran mas que víctimas de un destino que se resistía a cambiar las reglas del juego, un destino al que solo un inesperado y ansiado gol podía gambetear con la necesaria viveza como para cambiar el resultado del partido.

A la luz del sueño todo parecía adquirir sentido. Giménez, su historia y particularmente mi etnografía, la que ahora se me revelaba no ya como una mera traducción sino como un acto de traición al sentido genuino de las cosas, un ejercicio de violencia semántica sistemáticamente ejercido sobre esos Otros donde intervienen arbitraria y sostenidamente nuestras propias creencias e historias, las cuales, nunca estamos del todo dispuestos a confesar. Mirado desde ese ángulo finalmente las palabras de Giménez parecían encerrar una enseñanza pedagógica: "en estos duros tiempos" mas que nunca "el Espíritu de Sacrificio" consiste en la inteligencia suficiente como para "discernir cuando hay que actuar, que debemos hacer" en un mundo en el que parece estar mas que claro que "los cobardes no escriben la Historia".

Después de todo se necesita mucha “violencia espiritual” para enfrentar semejante 'violencia semántica'.

\section{RECONCILIACION}

Las tres confesiones ponen sobre el tapete la manera en que los prejuicios - disciplinares, de creencia y de clase - actúan en el proceso de investigación y particularmente en qué medida y de qué manera motorizan valoraciones negativas sustentadas en la cercanía, cuestiones recurrentes en la historia de la antropología. En referencia a ello, Peter Fry (1984) en su análisis de la obra de Roger Bastide señala cómo los valoraciones ya positivas, ya negativas de ciertas prácticas religiosas como el candomblé y la umbanda no solo pueden constituirse en prejuicios sino también consolidar campos de investigación "legítimos" e "ilegítimos" en función de intereses y valoraciones subjetivas. Así, la valoración positiva de Roger Bastide sobre el candomblé -asociado a la idea de comunidad, 
igualitarismo, orden y control social, cosmología compleja y religiosidad - y negativa de la umbanda - asociada a los migrantes urbanos, el individualismo, sincretismo, anomalía, cosmología simple y magia - constituyen juicios de valor que tienen consecuencias criticas en el interior del campo académico y en las valoraciones y juicios que una sociedad se forma de ellos. Si las oposiciones no son ajenas a una antropología francesa de la que Roger Bastide es ancestro, sus apreciaciones deben evaluarse como parte de una distinción relevante que oportunamente señalara Edmund Leach (1967) entre los sentimientos que invoca un otro lejano que por ser tal permanece como no problemático y las contrariedades surgidas de un otro cuya cercanía nos resulta siempre conflictiva. En este sentido, si la valoración positiva del candomblé por parte de Bastide no es muy distinta a esa sobrevaloración tácita de las prácticas y creencias nativas, la valoración negativa de la umbanda tampoco es ajena a una tendencia a negar las creencias y prácticas religiosas ajenas no solo por permanecer fuera de nuestro horizonte de creencias sino también por el hecho de resultarnos demasiado familiares y cotidianas. Algo que, a pesar de nuestra familiaridad con lo ajeno, no parece eximirnos de nuestra impericia para desandar lo obvio cuando de prácticas tanto ajenas como prójimas se trata. Este juego entre la familiaridad y el exotismo, la cercanía y la distancia, en el que se despliega la labor etnográfica, nos obliga a pensar críticamente en torno al proceso de traducción entendido no ya como un espacio neutro de producción del conocimiento, sino fundamentalmente como un "campo de negociación" (Conklin y Graham 1995) que regula las relaciones entre nosotros y los otros y que, dado su carácter pragmático, presupone procesos creativos de confrontación, avenencia e innovación a partir de los cuales ambos interlocutores desarrollan sistemas de comunicación e intercambio que tienen como meta el logro de sus propios objetivos. Esta perspectiva, lejos de desarticular la práctica etnográfica y su importancia en la producción de conocimiento, permite contextualizar política e ideológicamente nuestra labor al tiempo de entender el encuentro etnográfico como un espacio mutuamente construido cuya explicación, si bien no se agota en la retórica de la dominación y la resistencia, actualiza relaciones asimétricas de larga data que se sustentan en una doble moral que solo reconoce las Diferencias al costo de ecualizarlas para volverlas asequibles a nuestra mirada (Augé 1993; Conklin y Graham 1995), una práctica nada exótica y cotidiana de nuestra actualidad.

Ana M aria Spadafora é docente de la Facultad de Filosofía y Letras, Instituto de Ciencias Antropológicas de la Universidad de Buenos Aires; docente de la Facultad Latinoamericana de Ciencias Sociales (FLACSO); e Investigadora del Consejo Nacional de Investigaciones Científicas y Técnicas (CONICET) de Argentina 
Ana Maria Sapadafora

\section{NOTAS}

1 Quiero agradecer especialmente por los comentarios realizados sobre este artículo al colega y amigo Dr. Alejandro Frigerio, cuya buena disposición y labor redundan en un invalorable aporte a la Antropología de la Religión en la Argentina. 


\section{REFERÊNCIAS BIBLIOGRÁFICAS}

AUGÉ, Marc. 1993. El genio del paganismo. Barcelona: Muchnic.

BEEMAN, William. 1993. "The anthropology of theater and spectacle". Annual Review of Anthropology 22.

CONKLIN, Betty \& Laura Graham. 1995. "The Shifting Middle Ground: Amazonian Indians and Eco-Politics". American Anthropologist 97(4):695-710.

CORDEU, Edgardo y Alejandra Siffredi. 1971. De la algarroba al algodón. M ovimientos Milenaristas del Chaco Argentino. Buenos Aires: J uárez Eds. etnía 12: 14-18.

1973. "En torno a los tobas y el milanarismo. Una respuesta crítica". Actualidad Antropológica, Suplemento de

CORDEU, Edgardo y Mercedes de los Ríos. 1982. “Un enfoque estructural de las variaciones socioculturales de los cazadores recolectores del Gran Chaco. Suplemento Antropológico 1(1):147-160.

FABIAN, J ohannes. 1983. Time and The Other. How Anthropology makes its objetct. New York: Columbia University Press.

FRIGERIO, Alejandro. 1994 "Para entender mejor al Pastor Giménez". Buenos Aires. mimeo.

FRY, Peter. 1984. “Gallus africanus est, ou, como Roger Bastide se tornou africano no Brasil”. FOLHETIM, Folha de São Paulo 15/7/1984, pp.7-10.

GALLIANO, Gabriel. 1994. "Milenarismo pentecostal. Pobreza urbana e interacción social en el Gran Buenos Aires". En A. Frigerio (comp.), El Pentecostalismo en la Argentina. Buenos Aires: Centro Editor de América Latina.

GARMA NAVARRO, Carlos. 1991. "Interpretando la antropología interpretativa”. Alteridades 1(1).

GEERTZ, Clifford. 1983. "From the native's point of view". En Local Knowledge.Further essays in interpretive anthropology. New York: Basic Books.

GELLNER, Ernest. 1994. Posmodernismo,Razón y Religión. Buenos Aires: Paidos.

GOFFMAN, Erving. 1981. “La presentación de la persona en la vida cotidiana”. Buenos Aires: Amorrortu.

CLIFFORD, J ames \&G. Marcus (eds). 1986. Writing Cultures. The poetics and politics of ethnography. Berkeley, CA: University of California Press.

LEACH, Edmund. 1967. Nosotros y los otros. En Un Mundo en Explosión. Barcelona: Anagrama.

MILLER, Elmer. 1979. Los tobas argentinos. Armonía y disonancia en una sociedad. México, DF: Siglo XXI.

ORO, Ari Pedro. 1992. "Neo-pentecostalismo". Cadernos de Antropología 9. Porto Alegre: Universidade Federal do Rio Grande do Sul, Programa de Pós-Graduação em Antropologia Social.

SAGASETA, J ulia Elena. 1991. "La experimentación en el teatro argentino actual”. Cuadernos de Investigación Teatral 1(1). Teatro Municipal General San Martín, Municipalidad de la Ciudad de Buenos Aires.

SCHECHNER, Richard. 1988. Performance Theory. New York: Routledge.

SEGATO, Rita. 1993. “Una paradoja del relativismo. El discurso de la antropología frente a lo sagrado”. Scripta Ethnologica. Buenos Aires: CAE /CONICET. 
Ana Maria Sapadafora

SIFFREDI, Alejandra. 1975/76. Movimenti social-religiosi fra gli indios del Gran Chaco. La Critica Sociologica 36:167-205. Universidad de Roma.

SPADAFORA, Ana María. 1994. Creencias milenaristas e identidad religiosa. En A. Frigerio (comp.), El Pentecostalismo en la Argentina. Buenos Aires: Centro Editor de América Latina. 1996. Informe Final. Beca de Perfeccionamiento. Secretaría de Ciencia y Tecnología/ CONICET.

TURNER, Victor. 1982. From ritual to theater. The human seriousness of play. New York: PAJ Publications. 1988. El proceso ritual. Estructura y antiestructura. Madrid: Taurus.

. 1992. The Anthropology of Performance. New York: PAJ Publications.

WRIGHT, Pablo. 1988. “Tradición y aculturación en una organización sociorreligiosa Toba cotemoporánea”.Cristianismo y Sociedad. 95: 71-87.

. 1990. “Crisis, enfermedad y poder en la Iglesia Cuadrangular Toba”. Cristianismo y Sociedad. 105: 15-37.

1994a. "Perspectivas teóricas en la antropología de los movimientos sociorreligiosos en el Chaco Argentino". En A. Barabas (comp.), Religiosidad y resistencia hacia fin de milenio. Quito: Abya Yala.

1994b. “Experiencia, intersubjetividad y existencia. Hacia una teoría práctica de la etnografía”. Runa. Archivo para las Ciencias del Hombre XXI:347- 374.

. 1998. "Cuerpos y espacios plurales. Sobre la razón espacial de la práctica etnográfica". Serie Antropología. Brasília: UnB/Departamento de Antropología.

WYNARCZYK, Hilario y Pablo Semán. 1994. “Campo evangélico y pentecostalismo en la Argentina”. En A. Frigerio (comp.), El Pentecostalismo en la Argentina. Buenos Aires: Centro Editor de América Latina. 
La Circularidad de la Experiencia de Campo: poder y desigualdad en la producción del conocimiento

\section{La circularidad de la experiencia de campo: poder y desigualdad en la producción del conocimiento}

\section{RESUMEN}

A partir de mi experiencia de campo com movimientos pentecostales urbanos y com grupos indigenas, el trabajo analiza cómo actúan los prejuicios - disciplinares, de creencia y de clase - a lo largo del proceso de investigación. Sostenemos que dichos prejuicios tienden a consolidar relaciones asimétricas de larga data sustentándose en valoraciones negativas sobre una otredad cuya cercanía es eminentemente conflictiva.

PALABRAS-CLAVE: investigación de campo, movimientos pentecostales, grupos indígenas

\section{A circularidade da experiência de campo: poder e desigualdade na produção do conhecimento}

RESUMO

A partir de minha experiência de campo com movimentos pentecostais urbanos e com grupos indígenas, neste trabalho analiso como os preconceitos - disciplinares, de convicção e de classe - atuam ao longo do processo de investigação. Sustento que a forma de relacionamento com o outro consolida relações assimétricas persistentes, que se apóiam em avaliações negativas de "outros" cuja proximidadae é eminentemente conflitiva.

PALAVRAS-CHAVE: pesquisa de campo, movimentos pentecostais, grupos indígenas

The circularity of the Field Experience: power and inequality in the production of knowledge

ABSTRACT

Departing from field experience with evangelical urban movements and with indigenous groups, this paper analyses how disciplinarian, belief and class prejudices act along the investigation process. It is argued that these prejudices, sustained by negative evaluations of an other whose proximity is eminently conflicting, help to consolidate long term asymmetric relationships.

KEY WORDS: fieldwork, evangelical urban movements, indigenous groups 